\title{
Time-sensitive ambulatory orthopaedic soft-tissue surgery paradigms during the COVID-19 pandemic
}

\author{
Benjamin Tze Keong Ding ${ }^{1}$ (D) - Joshua Decruz ${ }^{1} \cdot$ Remesh Kunnasegaran ${ }^{1}$
}

Received: 22 April 2020 / Accepted: 6 May 2020 / Published online: 15 May 2020

(C) SICOT aisbl 2020

\begin{abstract}
Purpose Timing of surgery for orthopaedic injuries continues to evolve, as an improved understanding of biology, healing, and technological advances continues to challenge historical norms. With the growing COVID-19 pandemic stretching limited healthcare resources, postponing surgery becomes an inevitable and unenviable task for most orthopaedic surgeons, and a shift in outpatient paradigms is required to mitigate poor outcomes in patients.

Methods A scoping review of five databases on surgical timing and orthopaedic soft-tissue injuries was performed. All randomized controlled trials, longitudinal cohort studies, retrospective case series, systematic reviews, meta-analyses, and expert opinions were included for review, with 65 studies meeting the inclusion criteria.

Results Better outcomes appear to be associated with early surgery for subluxations ( $<1$ week), recurrent dislocations ( $>2$ episodes), ligamentous and tendinous injuries $(<2$ weeks), and bony avulsion injuries $(<3$ weeks). Spinal conditions with neurological compromise should be operated on within 24 hours and spinal instability within 72 hours to reduce the risk of complications and poor outcomes.

Conclusion Most soft-tissue orthopaedic injuries can be managed with outpatient ambulatory surgery in a semi-elective setting. As the paradigm for outpatient surgery shifts due to technological advances and the COVID-19 pandemic, it is critical for surgeons to time their surgery appropriately to maintain the high standards of orthopaedic practice.
\end{abstract}

Keywords COVID-19 $\cdot$ Pandemic $\cdot$ Orthopaedics $\cdot$ Surgery $\cdot$ Delayed surgery

\section{Introduction}

Acute musculoskeletal conditions account for $87 \%$ of all healthcare visits for traumatic injuries [1]. Timely surgery for the repair, reduction, or reconstruction of critical structures has the potential to improve outcomes and overall quality of life for patients. As the COVID-19 pandemic continues to wreak havoc on healthcare systems and limit facilities for surgically necessary procedures, it is essential that orthopaedic surgeons are still able to schedule timely surgery and advice patients based on the current literature.

Lankester et al. [2] categorized orthopaedic conditions requiring emergency surgery into three groups depending

Benjamin Tze Keong Ding

ding.tze.keong.benjamin@gmail.com

1 Department of Orthopaedic Surgery, Tan Tock Seng Hospital, 11 Jalan Tan Tock Seng, Singapore S308433, Singapore on the need for (1) urgent operative intervention, (2) early surgery during the next available semi-elective list with necessary sub-specialty expertise, or (3) conditions that rarely come to harm if operated on after a few days. While most fractures, mangled limbs, neurovascular injuries, compartment syndromes, and severe infections will still require urgent surgery, more procedures may now be performed in a delayed ambulatory setting without compromising patient care due to advances in technology and improved understanding of biology. Massey et al. recommended that most fracture fixations should be performed within two weeks of index injury [3], while DePhillipo recommended a list of acute surgically necessary soft-tissue injuries that should be operated on as elective-urgent procedures in the outpatient setting without guidance on critical timings [4]. As recommendations for time to surgery for sub-acute orthopaedic soft-tissue conditions are currently guided by expert opinions and historical perspectives, this paper aims to further assist surgeons by outlining surgical timings based on a review of the literature as summarized in Table 1. 
Table 1 Recommended time to surgery for conditions requiring time-sensitive orthopaedic ambulatory surgery

\begin{tabular}{|c|c|c|c|}
\hline \multicolumn{2}{|l|}{ Condition } & \multirow{2}{*}{$\begin{array}{l}\text { Recommended } \\
\text { time to surgery }\end{array}$} & \multirow{2}{*}{$\begin{array}{l}\begin{array}{l}\text { Level of } \\
\text { evidence }\end{array} \\
\text { II }\end{array}$} \\
\hline Shoulder & Unstable gleno-humeral joints following dislocation & & \\
\hline & Acute types III, IV, V, and VI Acromioclavicular joint dislocations & $<3$ weeks & IV \\
\hline & Acute/severe rotator cuff tears & $<3$ weeks & IV \\
\hline \multirow[t]{4}{*}{ Elbow } & Unstable elbow subluxations or dislocations & $<2$ weeks & III \\
\hline & Locked osteochondral defects of the elbow & $<2$ weeks & $\mathrm{V}$ \\
\hline & Distal biceps tendon tears & $<3$ weeks & III \\
\hline & Triceps tendon tears & $<12$ weeks & III \\
\hline \multirow[t]{3}{*}{ Hand and wrist } & Acute flexor tendon tears & $<3$ days & III \\
\hline & Unstable carpal dislocations/fracture dislocations & $<1$ week & III \\
\hline & Unstable phalangeal subluxations or dislocations & $<4$ weeks & IV \\
\hline \multirow[t]{3}{*}{ Foot and ankle } & Ankle fracture dislocation or subluxation with syndesmosis disruption & $<1$ day & $\mathrm{V}$ \\
\hline & Acute Achilles tendon rupture & $<2$ days & III \\
\hline & Acute ligament tears with ankle instability & $<2$ weeks & II \\
\hline \multirow[t]{6}{*}{ Knee } & Acute tendon ruptures (patellar or quadriceps) & $<1$ week & III \\
\hline & Dislodged osteochondral fractures & $<2$ weeks & II \\
\hline & Multi-ligament knee injury & 2-4 weeks & II \\
\hline & Anterior/posterior cruciate ligament avulsion injuries & $\begin{aligned}< & 3 \text { weeks } \\
& (<2 \text { weeks for tendinous avulsion })\end{aligned}$ & II \\
\hline & Meniscus tears & $<12$ weeks & V \\
\hline & Manipulations after total knee replacement & $<12$ weeks & IV \\
\hline \multirow[t]{4}{*}{ Hip } & Hip subluxation or dislocation that is not reducible or is unstable post-reduction & $<6 \mathrm{~h}$ & $\mathrm{~V}$ \\
\hline & Dislocated/unstable arthroplasties & $>2$ dislocations & $\mathrm{V}$ \\
\hline & Acute proximal hamstring ruptures & $<4$ weeks & IV \\
\hline & Locked hip secondary to intraarticular loose bodies or an incarcerated labrum & $<6$ months & II \\
\hline \multirow[t]{2}{*}{ Spine } & Neurological deficit or impending deficit that can be prevented by decompression & $<24 \mathrm{~h}$ & II \\
\hline & Spinal fractures with instability & $<3$ days & III \\
\hline
\end{tabular}

\section{Evidence review}

We performed a search of electronic databases (Pubmed, Embase, Scopus, Web of Science, Google Scholar) using the keywords "time to surgery," "early surgery," and "delayed surgery," which were subsequently matched to search terms "orthopaedic injury," "joint dislocation," "tendon rupture," "ligament rupture," "spinal injury," and "unstable arthroplasty." Published articles between January 2000 and March 2020 were retrieved, and their titles, abstracts, and full texts were reviewed for appropriateness. Inclusion criteria comprised of (1) randomized controlled trials, longitudinal cohort, and retrospective studies; (2) systematic reviews and metaanalyses; (3) expert opinions; (4) availability of full text; and (5) manuscript availability in English language. We excluded articles if they had (1) majority of study population under 21 years old, (2) studies conducted outside the time frame, and (3) long bone and peri-articular fractures.

\section{Shoulder conditions}

\section{Unstable gleno-humeral joints following dislocation}

An increasing number of dislocations and duration of dislocation have been shown to be associated with an increasing severity of soft-tissue pathology [5], glenoid or humeral head bony lesions [6], and gleno-humeral arthritis [7]. While surgical repair for first and second time dislocations remains controversial, those with $>$ two dislocations during initial immobilization or functional rehabilitation should be counseled for surgical stabilization of the shoulder due to the risk of progressive damage to the capsulolabral complex [5].

\section{Acute types III, IV, V, and VI acromioclavicular joint dislocations}

A review published by Song et al. [8] previously concluded that there was not enough high-quality evidence to perform a proper systematic review. For Rockwood III injuries, a Cochrane review 
by Tamaoki et al. [9] concluded that the evidence for operating on such conditions remains controversial and is currently guided by patient demographic, activity level, occupation, and handedness. Early surgical treatment, within three weeks of acute injury, is associated with better functional outcomes and satisfactory reduction when compared with the delayed procedures $(>3$ weeks) [8]. Biological augmentation with a tendon graft or anatomical reconstructive techniques are recommended for surgical repair after three weeks $[10,11]$.

\section{Acute/severe rotator cuff tears}

A biomechanical study showed that acute repairs within the first three weeks had better post-surgical viscoelastic properties, as tendons would stiffen if repair was delayed by $>$ three weeks. The delay in repair was also associated with decreasing greater tuberosity bone density, which may contribute to poor healing [12]. A systematic review by Mukovozov et al. showed a trend suggesting that surgeries performed within three months of an acute rotator cuff tear were linked to better post-operative range of motion and Constant scores [13]. The authors did conclude that their findings should be interpreted with caution due to the limitations and bias inherent in case series as 11 of the 15 studies were retrospective, and there was not randomized controlled trials available for analysis.

\section{Elbow conditions}

\section{Unstable elbow subluxations or dislocations}

Unstable elbow dislocations are commonly associated with lateral collateral ligament injuries, capsular ruptures, and fractures of the radial head and coronoid. While the evidence for early surgery for recurrent simple elbow dislocations is lacking, emergency $(<24$ hours) or early (4-14 days) surgery was associated with better range of motion, Mayo Elbow Performance Scores (MEPS), and reduced elbow stiffness than delayed surgery ( $>14$ days) for terrible triad of the elbow [14].

\section{Locked osteochondral defects of the elbow}

Osteochondral defects of the elbow may result in mechanical blocks to motion if not removed expediently. The elbow itself is very sensitive to developing stiffness due to fibrosis of the anterior joint capsule. Surgery should be performed within two weeks of the injury to allow early active mobilization and prevent complications of stiffness. Elbow capsular release can be considered if an elbow contracture of more than 30 degrees persists after six months of therapy [15].

\section{Distal biceps tendon tears}

Delayed biceps tendon repair ( $>3$ weeks) is associated with a higher rate of initial complications (neuropraxia, stiffness, rerupture, heterotopic ossification, infection) when compared with early repair ( $<3$ weeks). Despite the higher rate of initial complications, follow-up scores of functional outcomes using the American Shoulder and Elbow Surgeons (ASES) elbow questionnaire and Disabilities of the Arm, Shoulder, and Hand (DASH) score were not statistically significant during longterm follow-up of two to four years [16].

\section{Triceps tendon tears}

Triceps tendon tears are commonly associated with renal disease and delays in initial diagnosis [17]. In a review of 184 triceps tendon repairs, there was no difference in eventual discharge from medical care when comparing early $(<3$ weeks) or delayed (3-12 weeks) surgery. Triceps tendon could be directly repaired in all patients when surgery was performed within the first 12 weeks of injury [18].

\section{Hand/wrist conditions}

\section{Acute flexor tendon tears}

Intra-synovial flexor tendon ruptures do not heal satisfactorily without surgical interventions. Early surgery allows for early mobilization to prevent adhesions, prevents scar hypertrophy, and improves gliding function between tendon and sheath [19]. Surgery should ideally be performed within 3 days of injury, as delays to surgery lasting between three to seven days are associated with increased risk of major complications (stiffness, re-rupture) [20, 21].

\section{Unstable carpal dislocations/fracture dislocations}

Early ( $<1$ week) concentric reduction of unstable peri-lunate dislocations and fracture dislocations was associated with better clinical and radiological outcomes when compared with dislocations treated between seven and 45 days after injury. While timing of surgery affected outcomes, meticulous appraisal and appropriate fixation of both osseous and ligamentous pathology were more crucial in attaining better outcomes [22, 23].

\section{Unstable phalangeal subluxations or dislocations}

Acute injuries to finger joints result in joint distention via inflammation and haemarthrosis. Scarring and fibrosis will eventually form if the joint is allowed to remain in its resting flexed position and may cause adhesions along the tendons and soft tissue. Evidence suggests that outcomes are 
significantly improved when intervention for injuries in these joints is instituted within four weeks of injury, regardless of treatment modality. While patients rarely regain full range of motion, early concentric reduction to facilitate early motion exercises diminishes complications [24].

\section{Foot/ankle conditions}

\section{Ankle fracture dislocation or subluxation with syndesmosis disruption}

Early fixation, on the day or day after injury, is recommended for patients under 60 years old if the mortise is unstable or remains malreduced on manipulation and casting. External fixation devices can be used to maintain reduction in the event of soft-tissue compromise, and definitive fixation can be performed in one to two weeks after the soft tissue has settled [25].

\section{Acute Achilles tendon rupture}

Patients with acute Achilles tendon rupture who underwent surgery within 48 hours after the injury had better outcomes (Achilles Tendon Total Rupture Score) and a reduced number of adverse events (re-rupture, deep vein thrombosis) when compared with patients undergoing surgery after 72 hours and can be used as a guideline for optimizing Achilles tendon rupture treatment protocols [26].

\section{Acute ligament tears with ankle instability}

Surgery for lateral ankle ligamentous instability is warranted for extensive grade III lesions of all three lateral ankle ligaments and in high-level athletes [27]. Acute repairs $(<2$ weeks) are associated with better scores on the American Orthopaedic Foot and Ankle Society (AOFAS) clinical rating scale when compared with those who underwent late reconstruction (mean of 4.4 years) [28]. Persistently symptomatic patients who experience recurrent sprains and persistent pain for greater than six months should be considered for operative treatment [29].

\section{Knee conditions}

\section{Acute tendon ruptures (patellar or quadriceps)}

Acute quadriceps and patella tendon ruptures require prompt diagnosis and surgery within the first week of injury to achieve primary direct repair and prevent complications. Patients with such injuries to the functional extensor mechanism are usually diabetic with inherent poor tissue quality, and any non-functional and diseased tendons should be debrided back to a healthy edge to allow optimal healing [30].

\section{Dislodged osteochondral fractures}

While the only limiting factor for primary fixation of dislodged osteochondral fragments in adolescents appears to be the integrity of the fragment itself [31,32], primary fixation in adults after two weeks appears to be associated with poorer outcomes and is classically excised. As with most articular surfaces, fibrocartilage starts to form within ten days after the injury such that reduction of the osteochondral fragment becomes difficult or even impossible [33, 34].

\section{Multi-ligament knee injury}

The timing of surgical intervention for multi-ligamentous knee injury remains a contentious topic in current literature. Early surgery is less technically challenging due to the ease of identification of anatomic landmarks and planes with the potential for direct repair. Early surgery is however associated with increased risks of arthrofibrosis and compartment syndrome from fluid extravasation through capsular injuries. Delaying surgery to two to four weeks after injury allows time for reduction in swelling and interval capsular healing while still allowing for direct repair of bony avulsions or midsubstance collateral ligament ruptures [35]. Differences between early ( $<2$ weeks) and late ( $>6$ months) surgery were small in the early phases of recovery but were ultimately not statistically significant at long-term follow-up of two to eight years [36, 37].

\section{Anterior/posterior cruciate ligament avulsion injuries}

Cruciate ligament avulsion fracture reduction and fixation are associated with excellent outcomes if treated early and adequately, both in children and adults [38]. Reduction of the fracture fragment does not occur with manipulation in hyperextension, as the fracture fragment is usually displaced and lies in an empty non-articulating area of the joint [39, 40]. Arthroscopic anterior cruciate ligament (ACL) avulsion fixation within 72 hours was not associated with statistically significant improvement in Lysholm and International Knee Documentation Committee (IKDC) scores [41]. Current reviews of posterior cruciate ligament (PCL) avulsion injuries recommend fixation of bony fragments within three weeks of injury and tendinous repair within two weeks of injury [42-45].

\section{Meniscus tears}

Meniscal injuries can cause debilitating pain, instability, locking, and stiffness in patients when occurring in isolation 
or together with other knee pathologies. Early repair $(<3$ months) for traumatic meniscal injuries was associated with reduced pain, locking, catching symptoms, and need for subsequent surgical procedures [46, 47].

\section{Manipulations after total knee replacement}

Knee replacement surgeries may be complicated by persistent stiffness due to pain, poor rehabilitation, or prolonged immobilization. Early manipulation under anaesthesia ( $<12$ weeks) is associated with greater flexion gains, final range of motion, and higher knee society scores compared with those performed after 12 weeks [48]. While there may still be a benefit from manipulation up to 26 weeks, open arthrolysis may be needed in the event of any further surgical delays [49].

\section{Hip conditions}

\section{Hip subluxation or dislocation that is not reducible or is unstable post-reduction}

Hip dislocations usually occur during high-energy trauma and may remain subluxed or dislocated due to bony and soft-tissue injuries. The primary concern for surgeons would be the risk of chondral injury and subsequent avascular necrosis, which has been found to be correlated with the degree of initial trauma and the time during which the hip remains dislocated $[50,51]$. Concentric reduction within six hours of injury substantially decreases the incidence of such complications, and prompt reduction has become a universally accepted mandate in all cases of hip dislocations or persistent dislocating [15].

\section{Dislocated/unstable arthroplasties}

Closed reduction of unstable arthroplasties should be accompanied by 24 hours of rest followed by supervised therapy. For non-compliant patients and recurrent dislocations, bracing for six weeks and avoidance of adduction and internal rotation for three months for posterior approaches to the hip are recommended followed by strengthening of the pelvicrural muscles [52]. Any surgery for hip dislocations should be sufficiently worked up to identify the cause of dislocation (infection, massive haematoma, implant malposition), and open reduction is mandatory within hours in the event of neurological compromise. Otherwise, surgery for recurrent dislocations should be reserved for patients with $>$ two dislocations [53].

\section{Acute proximal hamstring ruptures}

In young, active patients, surgical treatment is usually warranted to allow early return to activity and improved quality of life [54]. Complete 3-tendon tears and 2-tendon tears/ avulsions with $>2$-cm retraction should undergo surgical repair within the first four weeks of injury. Surgery performed after four weeks poses a technical challenge due to increased scarring, difficulty of sciatic nerve neurolysis, and mobilization of the retracted tendons $[55,56]$.

\section{Locked hip secondary to intraarticular loose bodies or an incarcerated labrum}

Conservative therapy for hip labral tears, femoro-acetabular impingement, and chondral damage in symptomatic patients should be limited to a maximal period of six months, as patients who underwent surgery after six months had significantly poorer results (Harris Hip Score) and an increased need for revision surgery [57]. To the author's knowledge, there is no current literature on the effects of delayed surgery in patients with an acute locked hip, but any intervention should be performed at an even earlier date to prevent further cartilaginous injury, stiffness, and complications of immobility.

\section{Spine conditions}

\section{Neurological deficit or impending deficit that can be prevented by decompression}

Early ( $<24$ hours) and ultra-early surgery $(<8-12$ hours) for acute spinal cord injury are associated with improved neurological recovery and shorter hospitalizations [58, 59]. No significant differences were reported in the rate of complications (mortality, neurologic deterioration, pneumonia, or pressure ulcers) between early ( $<24$ hours) and late ( $>24$ hours) decompression groups [60]. While various thresholds exist in the literature, pre-clinical and clinical evidences show a clear trend of clinically and statistically meaningful improvement in motor scores when surgery is performed within 24 hours of injury, especially in patients with cervical cord injury and traumatic central cord syndrome [59, 61].

\section{Spinal fractures with instability}

Unstable cervical or thoracolumbar spinal fractures may lead to neurological compromise and permanent dysfunction without early intervention. Care of such patients is also complicated by bulky orthoses and increased manpower for daily tasks due to the need to maintain spinal nursing. The National Trauma Data Bank found that the majority of patients with spinal fractures underwent operative fixation within three days, with these patients having less complications (skin breakdown, acute respiratory distress syndrome, venous thromboembolism, progression of neurological insult, pneumonia, urinary tract infection) and requiring less resources [62-64]. These findings were replicated in patients who 
sustained polytrauma [65] and should be prioritized before the management of other long bone and peri-articular fractures in these patients. Various spinal colleges throughout the world have different guidelines for timing of surgery, and a universally accepted algorithm remains elusive for the time being. While surgical timings remain controversial, the recommendation seems to be for hospitalization of the patient for expedited surgery and to proceed when surgical expertise and an operating list become available.

\section{Conclusion}

Orthopaedic surgical practice will continue to evolve with increased sophistication of surgical techniques and technological advances. For acute traumatic injuries in the ambulatory surgery setting, better outcomes appear to be associated with early surgery for subluxations ( $<1$ week), recurrent dislocations ( $>2$ episodes), ligamentous and tendinous injuries $(<2$ weeks), and bony avulsion injuries ( $<3$ weeks). Spinal conditions with neurological compromise should be operated on within 24 hours, and spinal instability within 72 hours. These patients should be hospitalized for serial reviews and expedition of surgery instead.

Acknowledgments The authors would like to thank the department, healthcare workers, and the patients for their contributions in the fight against COVID-19.

Author contributions All authors contributed equally in the literature review, manuscript writing, and review, and approved the version submitted for publication. BTKD is the principal investigator and guarantor of this work and, as such, takes responsibility for the integrity of the data in the study and the accuracy of the content provided and had final responsibility for the decision to submit for publication.

\section{Compliance with ethical standards}

Conflict of interest The authors declare that they have no conflict of interest.

\section{References}

1. Jaimo Ahn ADN, Gudrun Mirick, Anna N Miller (2016) The Burden of musculoskeletal diseases in the United States, Fourth Edition National Institutes of Health. https://www. boneandjointburden.org/fourth-edition/vb0/traumatic-injuries. Accessed April 14, 20202020

2. Lankester BJ, Paterson MP, Capon G, Belcher J (2000) Delays in orthopaedic trauma treatment: setting standards for the time interval between admission and operation. Ann R Coll Surg Engl 82(5): 322-326

3. Massey PA, McClary K, Zhang AS, Savoie FH, Barton RS (2020) Orthopaedic surgical selection and inpatient paradigms during the coronavirus COVID-19 pandemic. JAAOS - Journal of the
American Academy of Orthopaedic Surgeons Publish Ahead of Print. https://doi.org/10.5435/jaaos-d-20-00360

4. DePhillipo NN, Larson CM, O'Neill OR, LaPrade RF (2020) Guidelines for ambulatory surgery centers for the care of surgically necessary/time-sensitive orthopaedic cases during the COVID-19 pandemic. JBJS Latest Articles. https://doi.org/10.2106/jbjs.20. 00489

5. Habermeyer P, Gleyze P, Rickert M (1999) Evolution of lesions of the labrum-ligament complex in posttraumatic anterior shoulder instability: a prospective study. J Shoulder Elb Surg 8(1):66-74. https://doi.org/10.1016/s1058-2746(99)90058-7

6. Denard PJ, Dai X, Burkhart SS (2015) Increasing preoperative dislocations and total time of dislocation affect surgical management of anterior shoulder instability. Int J Shoulder Surg 9(1):1-5. https:// doi.org/10.4103/0973-6042.150215

7. Sugaya H, Moriishi J, Dohi M, Kon Y, Tsuchiya A (2003) Glenoid rim morphology in recurrent anterior glenohumeral instability. J Bone Joint Surg Am 85(5):878-884. https://doi.org/10.2106/ 00004623-200305000-00016

8. Song T, Yan X, Ye T (2016) Comparison of the outcome of early and delayed surgical treatment of complete acromioclavicular joint dislocation. Knee Surg Sports Traumatol Arthrosc 24(6):19431950. https://doi.org/10.1007/s00167-014-3225-9

9. Tamaoki MJ, Belloti JC, Lenza M, Matsumoto MH, Gomes Dos Santos JB, Faloppa F (2010) Surgical versus conservative interventions for treating acromioclavicular dislocation of the shoulder in adults. Cochrane Database Syst Rev (8):Cd007429. https://doi.org/ 10.1002/14651858.CD007429.pub2

10. Beitzel K, Mazzocca AD, Bak K, Itoi E, Kibler WB, Mirzayan R, Imhoff AB, Calvo E, Arce G, Shea K (2014) ISAKOS upper extremity committee consensus statement on the need for diversification of the Rockwood classification for acromioclavicular joint injuries. Arthroscopy : the journal of arthroscopic \& related surgery : official publication of the Arthroscopy Association of North America and the International Arthroscopy Association 30(2): 271-278. https://doi.org/10.1016/j.arthro.2013.11.005

11. Beitzel K, Cote MP, Apostolakos J, Solovyova O, Judson CH, Ziegler CG, Edgar CM, Imhoff AB, Arciero RA, Mazzocca AD (2013) Current concepts in the treatment of acromioclavicular joint dislocations. Arthroscopy 29(2):387-397. https://doi.org/10.1016/j. arthro.2012.11.023

12. Galatz LM, Rothermich SY, Zaegel M, Silva MJ, Havlioglu N, Thomopoulos S (2005) Delayed repair of tendon to bone injuries leads to decreased biomechanical properties and bone loss. J Orthop Res 23(6):1441-1447. https://doi.org/10.1016/j.orthres.2005.05. 005.1100230629

13. Mukovozov I, Byun S, Farrokhyar F, Wong I (2013) Time to surgery in acute rotator cufftear: a systematic review. Bone Joint Res 2(7):122-128. https://doi.org/10.1302/2046-3758.27.2000164

14. Zhou C, Lin J, Xu J, Lin R, Chen K, Sun S, Kong J, Shui X (2018) Does timing of surgery affect treatment of the terrible triad of the elbow? Med Sci Monit 24:4745-4752. https://doi.org/10.12659/ msm.907146

15. Cohn S (2006) Complications in surgery and trauma. CRC Press

16. Haverstock J, Grewal R, King GJW, Athwal GS (2017) Delayed repair of distal biceps tendon ruptures is successful: a case-control study. J Shoulder Elb Surg 26(6):1031-1036. https://doi.org/10. 1016/j.jse.2017.02.025

17. Dunn JC, Kusnezov N, Fares A, Rubin S, Orr J, Friedman D, Kilcoyne K (2017) Triceps Tendon ruptures: a systematic review. Hand (New York, NY) 12(5):431-438. https://doi.org/10.1177/ 1558944716677338

18. Mirzayan R, Acevedo DC, Sodl JF, Yian EH, Navarro RA, Anakwenze O, Singh A (2018) Operative management of acute triceps tendon ruptures: review of 184 cases. Am J Sports Med 46(6):1451-1458. https://doi.org/10.1177/0363546518757426 
19. Yang G, Rothrauff BB, Tuan RS (2013) Tendon and ligament regeneration and repair: clinical relevance and developmental paradigm. Birth Defects Res C Embryo Today 99(3):203-222. https:// doi.org/10.1002/bdrc. 21041

20. Griffin M, Hindocha S, Jordan D, Saleh M, Khan W (2012) An overview of the management of flexor tendon injuries. Open Orthop Journal 6:28-35. https://doi.org/10.2174/ 1874325001206010028

21. Reito A, Manninen M, Karjalainen T (2019) The effect of delay to surgery on major complications after primary flexor tendon repair. J Hand Surg (Asian-Pacific Volume) 24(02):161-168. https://doi. org/10.1142/s2424835519500218

22. Herzberg G, Comtet JJ, Linscheid RL, Amadio PC, Cooney WP, Stalder J (1993) Perilunate dislocations and fracture-dislocations: a multicenter study. J Hand Surg 18(5):768-779. https://doi.org/10. 1016/0363-5023(93)90041-z

23. Komurcu M, Kurklu M, Ozturan KE, Mahirogullari M, Basbozkurt M (2008) Early and delayed treatment of dorsal transscaphoid perilunate fracture-dislocations. J Orthop Trauma 22(8):535-540. https://doi.org/10.1097/BOT.0b013e318183eb23

24. Kamnerdnakta S, Huetteman HE, Chung KC (2018) Complications of proximal interphalangeal joint injuries: prevention and treatment. Hand Clin 34(2):267-288. https://doi.org/10.1016/j.hcl.2017.12. 014

25. Association BO (2016) British Orthopaedic Association Standards for Trauma-the management of ankle fractures. British Orthopaedic Association. https://www.boa.ac.uk/standards-guidance/boasts. html. Accessed April 15, 20202020

26. Svedman S, Juthberg R, Edman G, Ackermann PW (2018) Reduced time to surgery improves patient-reported outcome after Achilles tendon rupture. Am J Sports Med 46(12):2929-2934. https://doi.org/10.1177/0363546518793655

27. Petersen W, Rembitzki IV, Koppenburg AG, Ellermann A, Liebau C, Brüggemann GP, Best R (2013) Treatment of acute ankle ligament injuries: a systematic review. Arch Orthop Trauma Surg 133(8):1129-1141. https://doi.org/10.1007/s00402-013-1742-5

28. Kitaoka HB, Lee MD, Morrey BF, Cass JR (1997) Acute repair and delayed reconstruction for lateral ankle instability: twenty-year follow-up study. J Orthop Trauma 11(7):530-535. https://doi.org/10. 1097/00005131-199710000-00012

29. Yasui Y, Murawski CD, Wollstein A, Takao M, Kennedy JG (2016) Operative treatment of lateral ankle instability. JBJS Rev 4(5). https://doi.org/10.2106/jbjs.rvw.15.00074

30. Volk WR, Yagnik GP, Uribe JW (2014) Complications in brief: quadriceps and patellar tendon tears. Clin Orthop Relat Res 472(3):1050-1057. https://doi.org/10.1007/s11999-013-3396-6

31. Megremis P, Megremis O, Margariti R (2019) Late repair, one year after a knee twisting injury, of a missed femoral trochlea osteochondral fragment, with bioabsorbable nails, in a 14-year-old boy. J Am Acadf Orthop Surg Glob Res Rev 3(8):e040. https://doi. org/10.5435/JAAOSGlobal-D-18-00040

32. Enea D, Busilacchi A, Cecconi S, Gigante A (2013) Late-diagnosed large osteochondral fracture of the lateral femoral condyle in an adolescent: a case report. J Pediatr Orthop B 22(4):344-349. https://doi.org/10.1097/BPB.0b013e3283602650

33. Kuhle J, Sudkamp NP, Niemeyer P (2015) Osteochondral fractures at the knee joint. Unfallchirurg 118(7):621-632; quiz 633-624. https://doi.org/10.1007/s00113-015-0033-8

34. Mashoof AA, Scholl MD, Lahav A, Greis PE, Burks RT (2005) Osteochondral injury to the mid-lateral weight-bearing portion of the lateral femoral condyle associated with patella dislocation. Arthroscopy : the journal of arthroscopic \& related surgery : official publication of the Arthroscopy Association of North America and the International Arthroscopy Association 21(2):228-232. https:// doi.org/10.1016/j.arthro.2004.09.029
35. Cox CL, Spindler KP (2008) Multiligamentous knee injuriessurgical treatment algorithm. N Am J Sports Phys Ther NAJSPT 3(4):198-203

36. Tzurbakis M, Diamantopoulos A, Xenakis T, Georgoulis A (2006) Surgical treatment of multiple knee ligament injuries in 44 patients: 2-8 years follow-up results. Knee Surg Sports Traumatol Arthrosc 14(8):739-749. https://doi.org/10.1007/s00167-006-0039-4

37. Liow RY, McNicholas MJ, Keating JF, Nutton RW (2003) Ligament repair and reconstruction in traumatic dislocation of the knee. J Bone Joint Surg British volume 85(6):845-851

38. Chouhan DK, Dhillon MS, John R, Khurana A (2017) Management of neglected ACL avulsion fractures: a case series and systematic review. Injury 48(Suppl 2):S54-s60. https://doi. org/10.1016/s0020-1383(17)30495-3

39. Meyers MH, McKeever FM (1970) Fracture of the intercondylar eminence of the tibia. J Bone Joint Surg Am 52(8):1677-1684

40. Zaricznyj B (1977) Avulsion fracture of the tibial eminence: treatment by open reduction and pinning. J Bone Joint Surg Am 59(8): $1111-1114$

41. Sundararajan SR, Rajasekaran S, Bernard SL (2011) Displaced anterior cruciate ligament avulsion fractures: arthroscopic staple fixation. Indian J Orthop 45(4):324-329. https://doi.org/10.4103/00195413.82336

42. Katsman A, Strauss EJ, Campbell KA, Alaia MJ (2018) Posterior cruciate ligament avulsion fractures. Curr Rev Musculoskelet Med 11(3):503-509. https://doi.org/10.1007/s12178-018-9491-2

43. Hoogervorst P, Gardeniers JW, Moret-Wever S, van Kampen A (2010) Pseudo-arthrosis repair of a posterior cruciate ligament avulsion fracture. Knee Surg Sports Traumatol Arthrosc 18(11):16121616. https://doi.org/10.1007/s00167-010-1114-4

44. Trickey EL (1980) Injuries to the posterior cruciate ligament: diagnosis and treatment of early injuries and reconstruction of late instability. Clin Orthop Relat Res 147:76-81

45. Singla R, Devgan A, Gogna P, Batra A (2014) Fixation of delayed union or non-union posterior cruciate ligament avulsion fractures. $\mathrm{J}$ Orthop Surg 22(1):70-74. https://doi.org/10.1177/ 230949901402200118

46. Venkatachalam S, Godsiff SP, Harding ML (2001) Review of the clinical results of arthroscopic meniscal repair. Knee 8(2):129-133. https://doi.org/10.1016/s0968-0160(01)00061-8

47. Beaufils P, Becker R, Kopf S, Matthieu O, Pujol N (2017) The knee meniscus: management of traumatic tears and degenerative lesions. EFORT Open Rev 2(5):195-203. https://doi.org/10.1302/20585241.2.160056

48. Mamarelis G, Sunil-Kumar KH, Khanduja V (2015) Timing of manipulation under anaesthesia for stiffness after total knee arthroplasty. Ann Transl Med 3(20):316. https://doi.org/10.3978/j. issn.2305-5839.2015.10.09

49. Kornuijt A, Das D, Sijbesma T, de Vries L, van der Weegen W (2018) Manipulation under anesthesia following total knee arthroplasty: a comprehensive review of literature. Musculoskelet Surg 102(3):223-230. https://doi.org/10.1007/s12306-018-0537-9

50. Rodriguez-Merchan EC, Goddard NJ (2000) Traumatic dislocation of the hip. Clin Orthop Relat Res 377:2-3

51. Rodríguez-Merchán EC, Goddard NJ (2000) Editorial Comment. A Publication of The Association of Bone and Joint Surgeons ${ }^{\circledR}$ CORR® 377:2-3

52. Zahar A, Rastogi A, Kendoff D (2013) Dislocation after total hip arthroplasty. Curr Rev Musculoskelet Med 6(4):350-356. https:// doi.org/10.1007/s12178-013-9187-6

53. Bourne RB, Mehin R (2004) The dislocating hip: what to do, what to do. J Arthroplast 19(4 Suppl 1):111-114. https://doi.org/10.1016/ j.arth.2004.02.016

54. Cohen S, Bradley J (2007) Acute proximal hamstring rupture. J Am Acad Orthop Surg 15(6):350-355. https://doi.org/10.5435/ 00124635-200706000-00004 
55. Harris JD, Griesser MJ, Best TM, Ellis TJ (2011) Treatment of proximal hamstring ruptures-a systematic review. Int J Sports Med 32(7):490-495. https://doi.org/10.1055/s-0031-1273753

56. Moatshe G, Chahla J, Vap AR, Ferrari M, Sanchez G, Mitchell JJ, LaPrade RF (2017) Repair of proximal hamstring tears: a surgical technique. Arthrosc Tech 6(2):e311-e317. https://doi.org/10.1016/ j.eats.2016.10.004

57. Aprato A, Jayasekera N, Villar R (2012) Timing in hip arthroscopy: does surgical timing change clinical results? Int Orthop 36(11): 2231-2234. https://doi.org/10.1007/s00264-012-1655-x

58. Wilson JR, Tetreault LA, Kwon BK, Arnold PM, Mroz TE, Shaffrey C, Harrop JS, Chapman JR, Casha S, Skelly AC, Holmer HK, Brodt ED, Fehlings MG (2017) Timing of decompression in patients with acute spinal cord injury: a systematic review. Glob Spine J 7(3 Suppl):95s-115s. https://doi.org/10.1177/ 2192568217701716

59. Fehlings MG, Vaccaro A, Wilson JR, Singh A, Cadotte DW, Harrop JS, Aarabi B, Shaffrey C, Dvorak M, Fisher C, Arnold P, Massicotte EM, Lewis S, Rampersaud R (2012) Early versus delayed decompression for traumatic cervical spinal cord injury: results of the Surgical Timing in Acute Spinal Cord Injury Study (STASCIS). PLoS One 7(2):e32037. https://doi.org/10.1371/journal.pone. 0032037

60. Wilson JR, Witiw CD, Badhiwala J, Kwon BK, Fehlings MG, Harrop JS (2020) Early surgery for traumatic spinal cord injury: where are we now? Glob Spine J 10(1 Suppl):84s-91s. https:// doi.org/10.1177/2192568219877860

61. Fehlings MG, Tetreault LA, Wilson JR, Aarabi B, Anderson P, Arnold PM, Brodke DS, Burns AS, Chiba K, Dettori JR, Furlan JC, Hawryluk G, Holly LT, Howley S, Jeji T, Kalsi-Ryan S, Kotter M, Kurpad S, Marino RJ, Martin AR, Massicotte E, Merli G,
Middleton JW, Nakashima H, Nagoshi N, Palmieri K, Singh A, Skelly AC, Tsai EC, Vaccaro A, Yee A, Harrop JS (2017) A clinical practice guideline for the management of patients with acute spinal cord injury and central cord syndrome: recommendations on the timing ( $\leq 24$ hours versus $>24$ hours) of decompressive surgery. Glob Spine J 7(3 Suppl):195s-202s. https://doi.org/10.1177/ 2192568217706367

62. O'Boynick CP, Kurd MF, Darden BV 2nd, Vaccaro AR, Fehlings MG (2014) Timing of surgery in thoracolumbar trauma: is early intervention safe? Neurosurg Focus 37(1):E7. https://doi.org/10. 3171/2014.5.focus 1473

63. Kerwin AJ, Griffen MM, Tepas JJ 3rd, Schinco MA, Devin T, Frykberg ER (2008) Best practice determination of timing of spinal fracture fixation as defined by analysis of the National Trauma Data Bank. J Trauma 65(4):824-830; discussion 830-821. https://doi. org/10.1097/TA.0b013e318182af7b

64. Croce MA, Bee TK, Pritchard E, Miller PR, Fabian TC (2001) Does optimal timing for spine fracture fixation exist? Ann Surg 233(6):851-858. https://doi.org/10.1097/00000658-20010600000016

65. Bliemel C, Lefering R, Buecking B, Frink M, Struewer J, Krueger A, Ruchholtz S, Frangen TM (2014) Early or delayed stabilization in severely injured patients with spinal fractures? Current surgical objectivity according to the Trauma Registry of DGU: treatment of spine injuries in polytrauma patients. J Trauma Acute Care Surg 76(2):366-373. https://doi.org/10.1097/TA.0b013e3182aafd7a

Publisher's note Springer Nature remains neutral with regard to jurisdictional claims in published maps and institutional affiliations. 